\title{
VIDA E ENVELHECIMENTO DA OBRA LITERÁRIA E DA OBRA LITERÁRIA EM TRADUÇÃO
}

\section{LIFE AND AGING OF LITERARY WORK AND OF LITERARY WORK IN TRANSLATION}

\author{
Mauricio Mendonça Cardozo \\ Universidade Federal do Paraná \\ Curitiba, Paraná, Brasil
}

\begin{abstract}
RESUMO: É corrente hoje em dia a noção de que a tradução seria "naturalmente" datada e, em razão disso, teria uma espécie de prazo de validade. Nesse sentido, enquanto as obras originais se perpetuariam numa forma de vitalidade perene, manifestada no que Walter Benjamin (2011) chamou de sua pervivência (Fortleben), em geral as traduções dessas obras evidenciariam naturalmente a fragilidade de sua condição provisória e efêmera: nessa perspectiva, diremos das traduções que elas simplesmente envelhecem. Mas dizer que as traduções envelhecem não seria já assumir que elas também se inscrevem em seu tempo e, portanto, que elas constituem, em alguma medida, uma forma singular de vida? Em outras palavras, seu envelhecimento não daria testemunho também de uma vida singular como obra? Partindo-se aqui do pressuposto de que, para além de representar uma forma de vida para a obra original, o texto traduzido também constitui, ele mesmo, uma forma singular de vida (CARDOZO, 2017), este trabalho se propõe a discutir algumas dessas questões, com o objetivo de repensar os sentidos da ideia de envelhecimento da tradução.
\end{abstract}

PALAVRAS-CHAVE: Tradução e vida; Tradução e envelhecimento; Tradução literária; Vida da obra literária

\begin{abstract}
It is not uncommon to assume nowadays that translations are always dated and, therefore, they have a kind of shelf life. In this sense, while original works perpetuate themselves in a form of perennial vitality, manifested in what Walter Benjamin (2011) called its Fortleben, translations of these works manifest the frailty of its provisional and ephemeral condition: it is from this perspective that we will say that translations simply grow old. However, in saying that, aren't we
\end{abstract}


assuming already that translations too are inscribed in time, and thus that they constitute in themselves a unique and singular form of life? In other words, would not their aging be a sign of the singularity of their form of life, of a form of life like works in themselves? Based on the assumption that, beyond representing a form of life for original works, translations also constitute in themselves a singular form of life (CARDOZO, 2017), this paper aims at discussing some of these issues, in order to rethink the possible meanings of the idea of aging of translations.

KEYWORDS: Translation and life; Translation and aging; Literary translation; Life of literary works 
E eu, menos estrangeiro no lugar que no momento. Caetano Veloso ${ }^{1}$

Juremir Machado da Silva, a propósito da tradução proustiana de Quintana: "Traduções envelhecem. São sempre provisórias" (SILVA, J. M., 2013). Christian Schwartz, a propósito de sua tradução do Frankenstein, de Mary Shelley: "[Mas] de uma coisa não se escapa, em tradução nenhuma: prazo de validade. Traduções envelhecem, não tem jeito" (SCHWARTZ, 2015). Alexandra Moreira da Silva, a propósito de sua retradução de uma peça de Molière em Portugal: "Como é sabido, não há traduções definitivas. As traduções - tal como os espetáculos - são efémeras, caducas, ultrapassáveis. As traduções envelhecem" (SILVA, A. M., 2009). Umberto Eco, em seu famoso livro Quase a mesma coisa: "Mas consideremos o fato, comprovado, de que as traduções envelhecem. O inglês de Shakespeare permanece sempre o mesmo, mas o italiano das traduções shakespearianas de um século atrás denuncia a própria idade" (ECO, 2007, p. 201). Ivo Barroso, a propósito do ofício do tradutor:

Sinto que as traduções envelhecem: o Fausto, de Castilho, embora excelente, é hoje de difícil leitura; de quando em vez, uma nova tradução pode reavivar o interesse dos leitores por obras que já pareciam peremptas (BARROSO, 2015, p. 5).

Ligia Chiappini, a propósito da tradução de Guimarães Rosa na Alemanha: "Quando se fala em reeditar, logo se diz: isso é uma tarefa muito longa, muito difícil e muito cara, pois é necessário 'retraduzir', já que as traduções envelhecem. Essa é uma das teorias. A outra diz que as boas traduções não envelhecem" (CHIAPPINI, 2008). Rafael Raffaelli, a propósito de suas traduções da obra de Shakespeare: "A obra clássica não envelhece, mas as traduções envelhecem" (RAFFAELLI apud MACÁRIO, 2016). O escritor alemão Michael Kleeberg, ele mesmo tradutor, em texto dedicado aos seus tradutores: "[...] existe um fenômeno estranho e inexplicável: as traduções envelhecem mais rapidamente do que os originais em sua língua de origem" (KLEEBERG, 2014).

Como resultado incidental de uma busca rápida pela internet - onde podemos encontrar com muita facilidade um sem número de manifestações semelhantes, seja como expressão daquele espaço indistinto que chamamos de senso comum, seja como expressão da produção crítica e teórica de pesquisadores renomados que têm a tradução ou a literatura por objeto, seja na voz dos próprios tradutores -, essas declarações dão testemunho do quanto a ideia de que $a$ tradução envelhece é amplamente corrente. Em suas nuances, essa ideia costuma vir acompanhada de diferentes percepções do envelhecimento (ou não) da chamada obra original, ora distinguindo-a categoricamente em nome de sua suposta perenidade, em oposição à efemeridade do texto traduzido, ora distinguindo-a quanto ao ritmo de envelhecimento, em nome de uma espécie de

\footnotetext{
${ }^{1}$ Da canção "O Estrangeiro", primeira faixa do disco Estrangeiro, de Caetano Veloso (1989).
} 
resistência maior da obra original à passagem do tempo, ora não fazendo maiores distinções.

Apesar da diversidade de opiniões quanto ao envelhecimento da tradução, como já podemos intuir da série inicial de citações, as discussões sobre essa questão, quando não se reduzem à naturalização estigmatizante da condição de envelhecimento, costumam se organizar, mais frequentemente, em torno de um mesmo eixo: o da relação do padrão de envelhecimento da tradução com o padrão de envelhecimento (ou não) do original. Ou seja, as reflexões se concentram majoritariamente em discutir se a tradução envelhece do mesmo modo ou de um modo diferente do que a obra original. Diante disso, Lenita Esteves, por exemplo, questiona: Não se explicita exatamente por que, mas as obras originais parecem sobreviver ao passar dos anos enquanto as traduções logo envelhecem e ficam inadequadas. Como se uma obra original não estivesse intimamente ligada à época e ao contexto que a produziram, o que poderia igualmente relegá-la ao envelhecimento e à inadequação. (ESTEVES, 2016, p. 657)

Em outras palavras, são mais raros, nesse cenário, os esforços reflexivos mobilizados para se repensar a própria noção de envelhecimento da tradução como uma questão. E quando nos aproximamos de colocar essa noção em discussão, a justificativa inequívoca (ainda que genérica) da inscrição das traduções na língua - e da respectiva transformação das línguas no curso do tempo - parece se impor como argumento cabal para esgotar tal esboço de discussão, antes mesmo que a hipótese de uma possível singularidade do envelhecimento do texto traduzido possa emergir como questão. Quando muito, o debate aborda indiretamente essa questão pela via da hipótese de que também alguns textos traduzidos possam transcender sua condição efêmera, como vimos na declaração de Chiappini (2008). Isso é o que também propõe, por exemplo, Mario Laranjeira, em sua Poética da Tradução, ao destacar, com Meschonnic, que: "Só envelhecem as traduções que não chegam a ser 'textos' [...] A traduçãotexto [para Laranjeira, uma tradução que $f a z$ obra] não envelhece, ou envelhece tanto quanto um texto [uma obra] pode envelhecer" (LARANJEIRA, 1993, p. 4142).

Esse viés da discussão, não raro fortemente tributário do pensamento benjaminiano (apesar de não ser este exatamente o caso de Laranjeira), costuma destacar a possibilidade de algumas traduções transcenderem seu fim instrumental mais imediato e se inscreverem como obra no plano da história, como se lhes fosse dada a possibilidade de driblarem a condição dita inevitável de efemeridade de toda tradução. No entanto, por mais que devamos reconhecer a contribuição desse tipo de esforço reflexivo para um redimensionamento contemporâneo da tradução como atividade de ordem crítica, tampouco as reflexões encaminhadas nessa direção costumam mobilizar um pensamento sobre a condição singular do envelhecimento da tradução.

Como contraponto às principais linhas de força desse debate, Marcelo Jacques de Moraes, em seu artigo "Envelhecimento e esquecimento, contratempos da tradução" (MORAES, 2017), aproxima-se bastante de um enfrentamento crítico do discurso do envelhecimento. Afastando-se de uma lógica mais corrente, que alia a resignação categórica à estigmatização sistemática da 
noção de envelhecimento, Moraes investe na possibilidade de se pensar essa mesma noção numa chave mais ampla e produtiva, como sintoma - ou aroma, se lembrarmos, aqui, de sua proposta de uma tradução odorante (idem, p. 43) - da inevitável inscrição da tradução $e$ do original no tempo. Nesse sentido, a percepção do envelhecimento, ao invés de remeter exclusivamente à negatividade de uma estigmatização, evidenciaria, antes, uma condição de inacabamento que é comum tanto à tradução quanto ao original, que é fundadora de suas próprias condições de vida. E é nessa perspectiva que, muito benjaminianamente, o autor propõe: [...] ela, a tradução, não cessa de solicitar, em contratempo, e a um só tempo, o seu próprio acabamento e o do original, a sua própria metamorfose e a do original, o seu próprio "crescimento" (BENJAMIN, 2011, p. 110) e o do original. Ou seja, no limite, a tradução não cessa de solicitar uma outra tradução, uma retradução, se quisermos, que reabre e reinterroga, no mesmo movimento, o original e suas precedentes traduções [...]. (MORAES, 2017, p. 37)

Para além da especificidade das questões que o autor propõe e discute em seu texto, um dos traços distintivos da reflexão de Moraes reside no fato de ela incorporar, explicita e consequentemente, uma dimensão temporal da tradução em seu pensamento, o que já a diferencia claramente da grande maioria das discussões sobre o assunto, em que até mesmo a noção de envelhecimento da tradução, apesar de tão inequivocamente temporal, não costuma ser discutida, senão, como uma condição de negatividade dessa prática - ou seja, sem que se considerem mais consequentemente os sentidos desse envelhecimento como expressão de uma relação da tradução com o tempo, ou ainda, como expressão da tradução enquanto tempo.

Ninguém há de negar que a tradução, como qualquer prática discursiva, tenha também uma dimensão temporal. A complexidade dessa dimensão, no entanto, não costuma ser considerada criticamente na maior parte das discussões que têm a tradução por objeto. Incorporar consequentemente a um pensamento sobre a tradução a dimensão temporal dessa prática é um passo decisivo para alçar a noção de envelhecimento da tradução a uma condição de questão.

\section{A QUESTÃO DO ENVELHECIMENTO, QUESTÃO DE VIDA}

Tudo o que envelhece, envelhece no tempo, com o tempo, como tempo. Por sua vez, se dizemos que algo envelhece é também porque conferimos a esse algo um dimensionamento vital, mesmo que nos sirvamos, no caso de cada algo particular, de diferentes noções de vida.

Dizemos, por exemplo, que o ser humano envelhece; mas também dizemos que as coisas envelhecem e, quando o fazemos, pressupomos nelas uma forma de vida, ainda que diversa daquela pressuposta no caso da vida do ser humano. E se, em geral, concebemos a vida do ser humano com certa complexidade, como uma condição vital que é constituinte do mundo - weltbildend, diria Heidegger ${ }^{2}-\mathrm{e}$

\footnotetext{
${ }^{2}$ A esse propósito, vide HEIDEGGER, 2004, especialmente p. 261-264, entre outras.
} 
que se inscreve num tempo de vida que é sempre um tempo de morte $e$ um tempo de vida, no caso da vida das coisas, mais comumente, conceberemos a vida nos limites de um sentido mais utilitário, de uma vida útil e, portanto, de uma forma de vida que vai muito pouco além de um sentido de depreciação, desgaste, perda de eficiência ou de viabilidade e que se inscreve como um tempo de vida, que, na prática, reduz-se quase exclusivamente a uma espécie de tempo de morte. Daí que, no uso corrente de nossa língua, não se confundam as diferentes nuances evocadas por expressões como, por exemplo, "homem de meia idade" e "pneu meia-vida", ainda que ambas se refiram mais ou menos a um mesmo meio de percurso (no tempo) de cada uma de suas respectivas dimensões vitais.

Nesse sentido, pensar a noção de envelhecimento da tradução a partir de um dimensionamento temporal dessa prática parece evidenciar, também, a necessidade de se pensar um dimensionamento da noção de vida que aí se pressupõe. Mas de que vida falamos quando falamos da vida da tradução?

Não cabe, aqui, ir mais longe nessa discussão ampla e complexa. Mas caberia destacar, ao menos, que se podemos pressupor uma relação determinante entre as noções de envelhecimento e vida, como sugerido acima, podemos pressupor também uma relação determinante entre a noção de vida da tradução e a concepção de tradução em questão.

Assim, poderíamos perguntar, por exemplo: de que forma de vida estamos falando quando nos referimos à tradução pensada num sentido estritamente instrumental, como prática mecânica e meramente reprodutora de sentidos, a qual não caberia, senão, cumprir o ideal essencialista e representacionista de dizer de novo a obra original em sua totalidade na língua de chegada - e nada além nem aquém disso, de modo que todo desvio desse ideal se configuraria, nessa perspectiva, como erro, defeito, deformação? E será que estaríamos falando de uma mesma forma de vida quando nos referimos à tradução como uma força necessariamente interventora, transformadora, criativa e crítica, que somente se projeta como uma forma de continuidade da obra original ao se inscrever de modo singular na condição inexoravelmente descontínua que se abre na relação entre essas duas obras?

Sem pretender responder, aqui, a essas perguntas, talvez possamos ao menos assumir que haveria uma distinção entre essas duas formas de vida da tradução e que a diferença entre elas seria significativa: da ordem de uma aproximação da primeira (da tradução como operação mecânica) a uma condição de vida meramente utilitária - sem-mundo ou, quando muito, pobre-de-mundo, para me apropriar aqui muito frouxamente das categorias de weltlos e weltarm, de Heidegger ${ }^{3}$ - ; e da ordem de uma aproximação da segunda (da tradução como operação crítica e transformadora) a uma condição mais complexa de vida, weltbildend, a uma forma de vida da tradução capaz de instaurar um lugar de singularidade no mundo.

Tendo essas considerações preliminares como pano de fundo, podemos agora retomar a discussão com vistas à questão do envelhecimento da tradução e da obra original.

\footnotetext{
${ }^{3}$ HEIDEGGER, 2004.
} 


\section{ENVELHECIMENTO E SINGULARIDADE DA TRADUÇÃO}

Todas as formas de leitura de uma obra se transformam ao longo do tempo, mas nem todas as formas de leitura têm necessariamente, como produto de seu gesto de leitura, outro texto. A crítica, o comentário e a tradução, por exemplo, além de representarem modos clássicos de leitura de uma obra, têm em comum, também, o fato de ganharem corpo como um novo texto.

A crítica e o comentário, de sua parte, têm, em geral, a particularidade não apenas de se fundarem ontologicamente numa relação metadiscursiva com a obra, mas também de sempre se explicitarem como tal, como um discurso "sobre" a obra. Nessa condição particular de vida, essa relação que lhes é constitutiva se manifesta, no gesto discursivo que lhe dá corpo, como uma forma mais ou menos evidente de espaçamento - entre aquilo que se diz e aquilo sobre o que se diz algo -, como uma espécie de fissura diferencial, que, a um só tempo: separa e distancia a crítica e o comentário daquilo que poderíamos circunscrever como seu objeto, mas também garante que essas práticas não se (con)fundam com seus objetos, possibilitando que elas se constituam como formas singulares de vida.

Assim, no gesto de leitura disto que se apresenta como um produto de leitura, não costuma haver grande risco de confusão entre as instâncias. Ao menos dentro do horizonte das expectativas mais convencionais, seria preciso uma dose razoável de ingenuidade ou desaviso para se ler a crítica como se fosse a própria obra. Quando muito, tomamos o dimensionamento que a crítica faz de certa obra pelo dimensionamento da obra; mas se o fazemos ocasionalmente - dispensando a nossa própria leitura do objeto, por qualquer que seja a razão -, não o fazemos sem saber que, nisso, aceitamos, às cegas, a voz da crítica pela voz da obra. E mesmo nesse caso, por mais que assumamos como nosso o dimensionamento da obra delineado pela crítica, ainda assim seria incomum confundirmos uma coisa com a outra. A crítica não se diz como se fosse a obra; a crítica fala sobre a obra. E como, para o leitor, em geral não há um risco de confusão dessas instâncias, a voz da crítica (do crítico) se manifesta como uma voz em si, como uma voz diferente da voz (das vozes) da obra que ela toma por objeto, garantindo-se assim, para a crítica, um estatuto mínimo de alteridade, de singularidade enquanto uma voz à parte, enquanto uma forma própria de vida.

Esse discurso crítico, como todas as formas de leitura, também sofrerá a ação do tempo, mas o tempo impactará sobre ele nessa sua condição de uma forma singular de vida ou, se quisermos, nessa sua condição autoral, original. É nesse sentido específico que poderíamos dizer que a crítica partilha, com a obra, de um estatuto de originalidade: não do estatuto de originalidade da obra (da obra que toma por objeto), mas de um estatuto de originalidade como obra (como o da obra que toma por objeto).

A tradução, como a crítica, também é uma daquelas formas de leitura de que deriva outro texto, como se costuma dizer. $\mathrm{E}$ se, ao menos do ponto de vista teórico, podemos dizer que a tradução partilha, com a crítica, da particularidade de também se fundar ontologicamente numa relação metadiscursiva com a obra original - ao menos na medida em que aceitemos a ideia de que todo discurso é 
um discurso sobre -, ao mesmo tempo ela se distancia da crítica por não se explicitar como tal. Em outras palavras: o texto traduzido, ao se apresentar como tradução de determinada obra, não se explicita como uma forma de vida fundada numa relação metadiscursiva, numa relação que o distancia, que o separa relacionalmente do texto que tem por objeto (o dito original) - apesar de, na prática, fazer exatamente isso.

Ora, sabemos que o texto traduzido só pode cumprir seu fim de dizer a obra original numa condição que é a de se constituir como um outro texto e, nesse sentido, todo texto traduzido, ao dizer o texto original de novo e para além de fazê-lo, fala também dessa relação, tem uma natureza metadiscursiva, que é determinante de sua dimensão crítica. Mas independentemente de sabermos muito bem disso ou de ignorarmos solenemente essa condição, é como uma forma única e indistinta de vida, é enquanto a própria obra original que o texto traduzido se oferece ao leitor. É nessa condição particular de uma fusão ou confusão de suas instâncias constitutivas - necessária e desejável, do ponto de vista de um horizonte mais instrumental da tradução - que os textos traduzidos vivem e sofrem a ação do tempo.

Mas se, com Lévinas e Derrida, não podemos assumir que sejamos contemporâneos nem a nós mesmos (CARDOZO, 2014, p. 121), quando se trata de dimensionar tudo aquilo que nos permitimos chamar de contemporâneo no dia a dia, fazemos um uso bem mais frouxo dessa noção; e talvez façamos isso do mesmo modo como assumimos que nossos conterrâneos falam "a mesma língua" que nós, ainda que saibamos que cada indivíduo faz sempre um uso próprio e sutilmente singular de sua língua - idiomático, no sentido mais particularmente próprio dessa expressão. Imersos no contexto linguístico de nossos conterrâneos, em geral, não nos é dado perceber aquilo que, quando deslocados deste para outro contexto linguístico, ainda numa mesma língua, configura um sotaque, uma diferença sutil no modo de ser em dada língua. Pois quem sabe não possamos aproximar aquela nossa relação com o que nos parece contemporâneo (por mais que distinto) dessa nossa relação com a percepção do próprio sotaque: em ambos os casos, é preciso uma forma de distanciamento, espacial ou temporal, para que $\mathrm{o}$ indistinto se nos apresente como tal, ganhando corpo como diferença.

À época de sua publicação, o texto traduzido, em toda a complexidade de vozes que o constitui, também se organizará inevitavelmente como uma forma singular de vida e, portanto, como uma forma particular de inscrição em seu tempo. Mas a não ser em casos muito particulares, em que o próprio projeto de tradução já se funda numa ideia forte de tensionamento de alguma dimensão do que lhe é então contemporâneo, de resto, grande parte das traduções serão lidas e percebidas, por seus leitores, num certo regime de indistinção - como se o texto traduzido nos falasse como um conterrâneo, sem sotaque.

Mas somos levados adiante pelo rio heraclitiano, e a passagem do tempo na forma das transformações da língua, da transformação dos panoramas críticos e estéticos, da transformação dos modos de leitura e de tradução, da transformação de nós mesmos etc. - acabará se manifestando como uma espécie de distanciamento nosso em relação ao texto traduzido, como se, aos poucos, fôssemos deixando de ser contemporâneos, como se não nos reconhecêssemos 
mais como conterrâneos. Nisso, aquele regime de indistinção, que outrora confundia as instâncias fundantes da natureza metadiscursiva dessa forma tradutória de vida, deixará de se impor implacavelmente e começaremos a perceber o texto traduzido em sua diferença constitutiva, como se agora flagrássemos nele algo como um sotaque - que não nos é mais indiferente justamente porque agora também perceberemos, nessa forma de vida, uma voz à parte.

Perceberemos então o texto traduzido como algo que nos é estrangeiro, ainda que menos no lugar que no momento, para fazer reverberar aqui o verso de Caetano Veloso, em epígrafe. E é com a percepção desse texto traduzido como uma forma de vida cheia de sotaques, estrangeira no tempo, que passamos então a conviver; mas não se trata de uma convivência fácil, pois estamos mais acostumados àquele regime de indistinção, em que a tradução não costuma evidenciar a condição complexa que a constitui. E assim que a percebemos, assim que nos damos conta de uma diferença que encorpa essa sua voz à parte, alguma coisa acontece. E como essa voz é sempre uma outra voz, em outro tempo, costumamos associar a consequente quebra desse regime de indistinção a um rompimento com certa percepção de contemporaneidade: tanto a nossa em relação ao texto traduzido (que se nos impõe agora como estrangeiro em nosso tempo) quanto aquela entre as diferentes vozes que o constituem. $\mathrm{E}$ ao invés de darmos ouvidos ao que dizem essas vozes que agora percebemos de modo menos indistinto, tendemos simplesmente a dizer, então, que a tradução ficou velha.

Contudo, aquilo que, em razão desse rompimento, costumamos reduzir automaticamente a uma perda de validade, a um envelhecimento da tradução, também pode ser percebido como uma espécie de perfume de seus tempos: não necessariamente no sentido da evocação dos olores ultrapassados do texto traduzido, de seus cheiros de antanho, mas, sim, no sentido específico da percepção dos contratempos e das extemporaneidades que fundam a singularidade de todo texto traduzido, que o fundam sempre como uma forma singular de vida.

Diante disso, ao invés de continuarmos associando automaticamente a quebra do regime de indistinção a uma percepção de envelhecimento - uma vez que, o que se nos apresenta, de fato, é apenas uma evidência de extemporaneidade - e ao invés de continuarmos naturalizando essa percepção de envelhecimento como um estigma, podemos ler essa diferença, que aí ganha corpo, justamente como o desnudamento de uma singularidade, como um desmascaro. E para concluir com Caetano o que começamos com Caetano, poderíamos simplesmente dizer que o rei está $n u . .$. e que é preciso despertar para essa nudez, mesmo que tudo insista em se calar frente ao fato de que o rei é mais bonito $\mathrm{nu}^{4}$.

\footnotetext{
${ }^{4}$ VELOSO, 1989.
} 


\section{REFERÊNCIAS}

BARroso, Ivo. Da Curiosidade à tradução como ofício. Belo Horizonte: Suplemento Literário, 2015, p. 4-5. Acesso em: 30 ago. 2017. Disponível em: $<$ https://ivonecbenedetti.files.wordpress.com/2015/08/suplementotradutoresversc3a3ofin al.pdf $>$.

BENJAMIN, Walter. A tarefa do tradutor. In: GAGNEBIN, Jeanne Marie (org). Escritos sobre mito e linguagem (1915-1921). Tradução Susana K. Lages e Ernani Chaves. São Paulo: Duas Cidades, Editora 34, 2011, p. 101-119.

CARDOZO, Mauricio Mendonça. Da morte, da vida e dos tempos de morte e de vida da tradução. Curitiba: Revista Letras, 2017, p. 46-59, n. 95.

CARDOZO, Mauricio Mendonça. Literatura e tradução: descontinuidades na ficção do outro. Brasília: Revista Brasileira de Literatura Comparada, 2014, p. $108-125$, n. 24.

CHIAPPINI, Ligia. Guimarães Rosa volta à Alemanha no ano de seu centenário. Belo Horizonte: O Debate, 2008. Disponível em: <http://www.odebate.com.br/ noticias-culturais/guimaraes-rosa-volta-a-alemanha-no-ano-de-seu-centenario-02-122008.html >. Acesso em: 30 ago, 2017.

ECO, Umberto. Quase a Mesma Coisa: experiências de tradução. Tradução Eliana Aguiar. Rio de Janeiro: Record, 2007.

ESTEVES, Lenita. Uma discussão sobre a prática da retradução com base no caso das republicações de obras de Clarice Lispector no exterior. Campinas: Trabalhos em Linguística Aplicada, 2016, p. 651-676, vol. 55, n. 3. Disponível em: $<$ http://www.scielo.br/scielo.php?lng=en\&tlng=pt\&\&nrm=iso\& script=sci_arttext\& \&pid=S0103-18132016000300651 $>$. Acesso em: 30 ago. 2017.

HEIDEGGER, Martin. Die Grundbegriffe der Metaphysik: Welt - Endlichkeit Einsamkeit. Frankfurt am Main: Klostermann, 2004, p. 261-264.

KLEEBERG, Michael. O irmão distante e ignorado do escritor - Por que tradutores devem ser idealistas. Tradução Claudia Cavalcanti. Literatura Alemã no Brasil, Goethe Institut, outubro de 2014. Acesso em: 30 ago. 2017. Disponível em: $<$ http://www.goethe.de/ins/br/lp/prj/dgb/uek/mag/pt13476215.htm>.

LARANJEIRA, Mário. Poética da tradução: do sentido à significância. São Paulo: Edusp, 1993.

MACÁRIO, Carol. Clássicos de Shakespeare ganham novas traduções em português. Diário Catarinense, Florianópolis, 21 de outubro de 2016. Disponível em: $<\underline{\text { http://dc.clicrbs.com.br/sc/entretenimento/noticia/2016/10/classicos- }}$ 
de-shakespeare-ganham-novas-traducoes-em-portugues-7861589.html >. Acesso em: 30 ago. 2017.

MORAES, Marcelo Jacques de. Envelhecimento e esquecimento, contratempos da tradução (com Walter Benjamin e Marcel Proust). Curitiba: Revista Letras, 2017, p. 35-45, n. 95.

SCHWARTZ, Christian. Dividi algumas madrugadas com "Frankenstein". Curitiba: Gazeta do Povo, 3 de novembro de 2015. Disponível em: $<$ http://www.gazetadopovo.com.br/caderno-g/literatura/dividi-algumas-madrugadascom-frankenstein-9mt3yj7sutppx4hvafkfgxn79>. Acesso em: 30 agosto 2017.

SILVA, Alexandra Moreira da. O meu querido baúzinho: retraduzir Molière. In: O Avarento (catálogo da peça encenada por Rogério de Carvalho). Porto, Portugal, 2009, p. 6-8. Disponível em: <www.tnsj.pt/home/media/pdf/Programa O Avarento final.pdf $>$. Acesso em: 30 agosto 2017.

SILVA, Juremir Machado da. Em busca da tradução ideal de Marcel Proust. Porto Alegre: Correio do Povo, 8 de abril de 2013. Acesso em: 30 ago. 2017. Disponível em: <http://www.correiodopovo.com.br/blogs/juremirmachado/2013/04/ 4046/em-busca-da-traducao-ideal-de-marcel-proust/>.

VELOSO, Caetano. Estrangeiro. Rio de Janeiro: Polygram, 1989. 1 CD.

Mauricio Mendonça Cardozo Maumeluco@gmail.com

Recebido em: 2/9/2017 Aceito em: 14/2/2018

Publicado em Abril de 2018 